\title{
Commentary
}

\section{Living in more than one place: capturing dual-local lives in the 2026 Census}

Elin Charles-Edwards The University of Queensland

Email: e.charles-edwards@uq.edu.au. Address: Queensland Centre for Population Research, School of Earth and Environmental Sciences, The University of Queensland, Brisbane, Australia 4072.

Paper received 5 March 2021; accepted 20 April 2021; published 31 May 2021

\section{Introduction}

The concept of "usual residence" is central to the collection of population data in the Australian Census of Population and Housing and the basis of Australia's official population statistic, the Estimated Resident Population. Usual residence is defined in the Census as "...the address at which a person lives or intends to live for six months or more" (ABS 2017). Growth in spatial mobility and a "pluralisation" of living arrangements makes that the notion of a single usual residence problematic for a growing share of the population (Schier et al. 2015). This includes second (vacation) homeowners (Atkinson et al. 2009), long-distance commuters (including Fly-in Fly-out workers), children living in shared custody arrangements (Stjernström and Strömgren 2012), and couples "living apart together" (Reimondos, Evans, and Gray 2011). Few data sources capture these populations in Australia, and available data lack detailed socioeconomic attributes and reliable spatial information which are critical for policy and planning. There are myriad applications of such data, ranging from the development of service population estimates (McKenzie, Martin, and Paris 2008) and emergency preparedness, to better understanding of residential multi-locality (Schier 2016) and regional population dynamics (Adamiak et al. 2017).

There are longstanding calls for the inclusion of a census question on dual or second residence (ABS 2007). A question on second residence was researched and tested for 2016 but not selected as it was "...difficult for respondents to understand" (ABS 2018) as well as having a significant cost impost. Despite renewed calls for inclusion in the 2021 census, a question on second residence was again rejected. Public submissions for the 2021 census also called for information on children living in multiple residences as part of shared care arrangements (ABS 2018), a form of dual-local living, but was not selected for inclusion. While there are certainly barriers to the inclusion of questions on dual residence including respondent burden, recall issues and cost, calls for better information on dual-local individuals and households are likely to persist and grow over time. 


\section{Proposed census questions}

Given the reticence of the ABS to include a question on dual residence in the census, it is illustrative to turn to other jurisdictions. Second or dual residence data can be collected directly via a targeted census question or indirectly as a by-product of the census enumeration strategy.

The England and Wales censuses have included questions on dual residence since 2011. Respondents are first asked, "Do you stay at another address for more than 30 days a year?". If respondents answered "yes" they were prompted to enter the full UK residential address or the country if the second residence was abroad. This was followed by a question asking respondents to nominate the type of residence from the following options: Armed forces base address; Another address when working away from home; Student's home address; Student's term-time address; Another parent or guardian's address; Holiday home; Other. The question has been retained for the 2021 census with only the addition of "Partner's house" as a response for the type of residence. The formulation used by the England and Wales censuses allows the identification of a range of dual-local arrangements including second homes, long-distance commuting, couples living apart together and children in shared custody arrangements.

A question on dual residence was included in the 2001 Italian census. Respondents were asked to "Indicate whether during the past 12 months (21 October 2000 - 21 October 2001) the person lived in accommodation or institutional household (e.g., relatives or friends house, barracks, hospital) other than the present". Respondents were then asked to nominate the number of days from a closed-response set. Persons living at another address for more than 90 days were asked to indicate if the person was currently absent, followed by the location of the accommodation (In this municipality; In another municipality; and abroad). A final question asked the reasons for absence. Pre-coded responses included: Work; Study; Vacation; Presence of relatives; Vacation; Previous usual residence; Other. The formulation used in the 2001 Italian census produced data on dual-local living arrangements tied to work, study, family and leisure. This question was not retained in the 2011 Italian census.

The 2020 United States census collected information on second homes (indirectly) as a by-product of its enumeration strategy. Individuals were directed to complete the census at their primary residence; however, homeowners were asked to complete a form for all properties owned and had the option of nominating these properties as seasonal homes. US census data on second homes are available back to the 1940s but are limited to the number and distribution of second homes across US states (US Census Bureau 2017). Information on the utilisation of seasonal homes, including the duration and purpose of use, is not available.

Following the example of the England and Wales census and the 2011 Italian census, the following suite of questions is proposed for the 2026 census in Australia (Figure 1). The proposed questions follow the same format as the England and Wales censuses. This is due to their simplicity and low respondent burden compared with the Italian formulation. An indirect data item, such as collected in the US, is rejected due to its inability to enumerate dual-local households, such as couples living apart together and Fly-in Fly-out arrangements. It is proposed that the 30-day threshold is replaced by the term "regularly" to reduce recall burden for respondents. Supplementary information is, however, required to provide respondents with the definition of "regular", here proposed as 
"recurring at uniform or fixed intervals e.g., weekly, monthly or seasonally". Respondents regularly living at more than two addresses should be instructed to select only one. The response set for question 2 is shorter than the England and Wales equivalent, and aims to capture the main forms of dual residence living in Australia including long distance commuting, children in shared custody, couples living apart together and second homeowners.

\begin{tabular}{|l} 
[1] In the past year, have you regularly stayed at another address? \\
[ ] No \\
[ ] Yes, write in other Australian address below \\
(Address write-in) \\
OR [ ] Yes, outside Australia, write in country \\
[2] What is that address? \\
[ ] Another address when working away from home \\
[ ] Parent or guardian's address \\
[ ] A partner's address \\
[ ] Holiday home \\
[ ] Other
\end{tabular}

Figure 1: Proposed census questions on dual residence

Source: author

\section{Discussion}

Census statistics on dual residence have several potential applications. In this section, three are described alongside a brief discussion of past research and existing data sources. These are: understanding the impacts of second home communities; the intensity, pattern and composition of long-distance commuting (LDC); and the distribution and characteristics of couples living apart together (LAT).

Second or vacation homes are a significant feature of regional landscapes in Australia and overseas. While there is extensive literature on second homes, the vast majority of papers are focused on Europe and North America. This literature points to the varied social (Gallent 2014), economic (Hilber and Schöni 2020; Velvin et al. 2013) and environmental (Hiltunen 2007; Næss et al. 2019) impacts of second homes. Besides improving our understanding of these varied impacts, accurate statistics on second homes would be useful for planning and provision of goods and services and emergency preparedness as part of service population estimates (McKenzie, Martin, and Paris 2008; CharlesEdwards, Bell, and Brown 2008). Several Australian sources provide partial insight into the number and distribution of second homes in Australia, including census counts of unoccupied dwellings, the National Visitor Survey (NVS), and the Household, Income and Labour Dynamics in Australia (HILDA) survey. At the 2016 Census, 11 per cent of private dwellings were unoccupied, up from 10 per cent in 2011. Over fifty per cent of private dwellings were unoccupied on census night in the Local Government Areas of Central Highlands, Robe, Queenscliffe, Tasman, Dandaraga, and Glamorgan/Spring Bay (Table 1). 
Table 1: Percentage of unoccupied private dwellings, selected Local Government Areas, 2016 Census

\begin{tabular}{|l|l|c|}
\hline Local Government Area & State & \% unoccupied private dwelling \\
\hline Central Highlands & Tasmania & 61 \\
\hline Robe & South Australia & 58 \\
\hline Queenscliffe & Victoria & 54 \\
\hline Tasma & Tasmania & 52 \\
\hline Dandaragan & Western Australia & 51 \\
\hline Glamorgan/Spring Bay & Tasmania & 50 \\
\hline
\end{tabular}

Source: ABS TableBuilder, 2016 Census

This statistic includes homes for sale, new homes yet to be occupied, homes in which the residents were absent on census night as well as second homes. No information on individuals using second homes is collected and thus the utility of census data is limited to identifying (potential) second home locations. Data have, however, been used for this purpose to good effect (see e.g., Frost 2004). The NVS collects data on trips and visitors to second homes (recorded as "own property") by Australians aged 15 years and over and includes information on trip activities as well as limited demographic data. In 2019, the NVS recorded almost 5 million overnight trips to second homes of a total of 117 million overnight trips (Tourism Research Australia 2021). Sampling variability is large at the local area level which limits the utility of these data for understanding second home impacts. HILDA collects data on second home ownership, along with a rich array of sociodemographic data, but does not collect any information on the location of second homes, again limiting their utility for studying impacts at the local area level. The proposed census questions on dual residence overcome the main shortcomings of the extant data sets providing reliable information on both the spatial distribution of second homes at the small area level as well as detailed information on the attributes of individuals visiting them.

Fly-in Fly-out (FIFO) and Drive-in Drive-out (DIDO) arrangements in the mining and construction sectors has disrupted the traditional relationship between place of usual residence and place of work in many parts of Australia (see the article by Haslam McKenzie in this issue). FIFO arrangements are just one form of long-distance commuting (LDC), an arrangement whereby people live beyond daily commuting distance from their workplace, necessitating several nights stay near their place of work before returning "home". Several studies have attempted to estimate the intensity (KPMG for the Minerals Council of Australia 2013), geography (Nicholas and Welters 2016), and characteristics (de Silva, Johnson, and Wade 2011) of LDC by cross-classifying a combination of census data on place of usual residence, place of enumeration and place of work and then applying some distance threshold that precludes daily commuting. Estimates of the extent of LDC vary depending on the classification method and distance thresholds used (Nicholas and Welters 2016). More accurate data on LDC is important to understand the social and economic impacts of LDC on individuals, families and communities. This may become increasingly important in the post-COVID-19 era with increased acceptance of working from home potentially facilitating more LDC arrangements.

A final application of the proposed question on dual residences relates to our understanding of couples living apart together (LAT). In recent decades, LAT has emerged as an important new household form, with estimates suggesting it involves around 10 per cent of the adult population in 
Western Europe, North America and Australasia (Duncan et al. 2014). Relatively little research on LAT has been undertaken in Australia (for exceptions see Tai et al. 2014 and Reimondos et al. 2011). Research from overseas suggests that the prevalence of these relationships is likely to increase over time, particularly among older adults (Benson and Coleman 2016). Growth in LAT relationships has the potential to impact average household size and dwelling demand (Reuschke 2010), as well as residential mobility (Wagner and Mulder 2015). While there are some survey data on LAT in Australia (e.g., HILDA), little remains known about the geographic distribution of these relationship and their impacts on urban form and spatial mobility.

The three applications described above highlight the growing complexity of living arrangements in Australia as well as the sustained efforts of researchers and policymakers to understand the intensity, composition and geography of dual-local arrangements and their impacts. The increase in dual-local individuals presents a challenge to traditional population statistics which are founded on the notion of a single place of usual residence. The growth in personal mobility, improvements in telecommunication technology and continued dismantling of traditional societal norms has the potential to increase the prevalence of such arrangements. Statistics on dual resident individuals and households are therefore likely to become more important over time.

\section{References}

ABS (2007) 2007.0 - Information Paper: Census of Population and Housing: ABS Views on Content and Procedures, 2011.

https://www.abs.gov.au/ausstats/abs@.nsf/latestproducts/53A690E9F185E186CA25737F00166A 7F?opendocument. Accessed on 28 February 2020.

ABS (2017) 2900.0 - Census of Population and Housing: Understanding the Census and Census Data, Australia, 2016. https://www.abs.gov.au/ausstats/abs@.nsf/Lookup/2900.0main+features62016. Accessed on 28 February 2020.

ABS (2018) 2007.0.55.001 - Census of Population and Housing: Topic Directions, 2021. https://www.abs.gov.au/ausstats/abs@.nsf/Lookup/by Subject/2007.0.55.001 2021 Main Features $\sim$ Topic directions $\sim$. Accessed on 28 February 2020.

Adamiak C, Pitkänen K and Lehtonen O (2017) Seasonal residence and counterurbanization: the role of second homes in population redistribution in Finland. GeoJournal 82: 1035-50. https://doi.org/10.1007/s10708-016-9727-x

Atkinson R, Picken F and Tranter B (2009) Home and away from home: the urban-regional dynamics of second home ownership in Australia. Urban Research \& Practice 2: 1-17. https://doi.org/10.1080/17535060902727009

Benson J and Coleman M (2016) Older Adults Developing a Preference for Living Apart Together. Journal of Marriage and Family 78: 797-812. https://doi.org/10.1111/jomf.12292

Charles-Edwards E, Bell M and Brown D (2008) Where people move and when: temporary population mobility in Australia. People and Place 16(1):21-30.

de Silva H, Johnson L and Wade K (2011) Long distance commuters in Australia: A socio-economic and demographic profile. Australasian Transport Research Forum 201, Adelaide. https://www.bitre.gov.au/sites/default/files/sp 005 DeSilva Johnson Wade.pdf

Duncan S, Phillips M, Carter J, Roseneil S and Stoilova M (2014) Practices and perceptions of living apart together. Family Science 5: 1-10. https://doi.org/10.1080/19424620.2014.927382 
Frost W (2004) A hidden giant: second homes and coastal tourism in South-Eastern Australia. In Hall CM and Müller D (eds.) Tourism, Mobility and Second Homes: Between Elite Landscape and Common Ground. Bristol: Channel View Publications; 162-173.

Gallent N (2014) The social value of second homes in rural communities. Housing, Theory and Society 31 : 174-191. https://doi.org/10.1080/14036096.2013.830986

Hilber $C$ and Schöni $O$ (2020) On the economic impacts of constraining second home investments. Journal of Urban Economics 118: 103266. https://doi.org/10.1016/j.jue.2020.103266

Hiltunen M (2007) Environmental Impacts of Rural Second Home Tourism - Case Lake District in Finland. Scandinavian Journal of Hospitality and Tourism 7: 243-65. https://doi.org/10.1080/15022250701312335

KPMG for the Minerals Council of Australia (2013) Analysis of the long distance commuter workforce across Australia. Canberra: Minerals Council of Australia.

McKenzie F, Martin J, and Paris C (2008) Fiscal policy and mobility: The impact of multiple residences on the provision of place-based service funding. Australasian Journal of Regional Studies 14: 53-71. https://www.anzrsai.org/assets/Uploads/PublicationChapter/245-McKenzieetal.pdf

Næss P, Xue J, Stefansdottir H, Steffansen R and Richardson T (2019) Second home mobility, climate impacts and travel modes: Can sustainability obstacles be overcome? Journal of Transport Geography 79: 102468. https://doi.org/10.1016/i.jtrangeo.2019.102468

Nicholas C and Welters R (2016) Exploring determinants of the extent of long distance commuting in Australia: accounting for space. Australian Geographer 47: 103-120. https://doi.org/10.1080/00049182.2015.1090300

Reimondos A, Evans A and Gray E (2011) Living-apart-together (LAT) relationships in Australia. Family Matters 87: 43-55. https://aifs.gov.au/publications/family-matters/issue-87/living-aparttogether-lat-relationships-australia

Reuschke D (2010) Living apart together over long distances - time-space patterns and consequences of a late-modern living arrangement. Erdkunde 64: 215-226. https://doi.org/10.3112/erdkunde.2010.03.01

Schier M, Hilti N, Schad H, Tippel C, Dittrich-Wesbuer A and Monz A (2015) Residential multi-locality studies - the added value for research on families and second homes. Tijdschrift voor Economische en Sociale Geografie 106: 439-452. https://doi.org/10.1111/tesg.12155

Stjernström $O$ and Strömgren M (2012) Geographical distance between children and absent parents in separated families. Geografiska Annaler. Series B, Human Geography 94: 239-253. https://doi.org/10.1111/j.1468-0467.2012.00412.x

Tai T, Baxter J and Hewitt B (2014) Do co-residence and intentions make a difference? Relationship satisfaction in married, cohabiting, and living apart together couples in four countries. Demographic Research 31: 71-104. https://doi.org/10.4054/DemRes.2014.31.3

Tourism Research Australia (2021) TRA Online. https://www.tra.gov.au/TRA-Online/tra-online. Accessed on 16 February 2020.

US Census Bureau (2017) Historical Census of Housing Tables: Vacation Homes https://www.census.gov/data/tables/time-series/dec/coh-vacation.html. Accessed on 16 February 2020.

Velvin J, Martin Kvikstad T, Drag E and Krogh E (2013) The impact of second home tourism on local economic development in rural areas in Norway. Tourism Economics 19(3): 689-705. https://doi.org/10.5367/te.2013.0216

Wagner M and Mulder C (2015) Spatial mobility, family dynamics, and housing transitions. KZfSS Kölner Zeitschrift für Soziologie und Sozialpsychologie 67: 111-135. http://doi.org/10.1007/s11577-015$\underline{0327-4}$ 